\title{
Advances in dry hopping for industrial brewing: a review
}

\author{
Fábio de Oliveira GOMES ${ }^{1}$, Bernardo Pontes GUIMARÃES², Duan CEOLA ${ }^{3}$ Grace Ferreira GHESTI (D)
}

\begin{abstract}
highly hopped and dry hopped beer production and consumption has increased steadily for the last twenty years, following the rise of craft breweries in the United States of America and the trend they set over the world. This overuse of hops offers some environmental, technological, and economic challenges for the beer industry. Researchers have been studying several ways to make beer more ecofriendly by promoting reuse of spent hops and increasing extraction yields. Dry hopping is a sizedependent process, making it feasible for craft breweries with their small scale production, but quite a challenge for larger tanks and breweries. Based on the literature and industrial experience from brewers, the aim of this research was to analyze and discuss different dry hopping methodologies for the brewing industry and how the parameters affect the final product. In order to shed light on this trending topic and to better aid brewers in choosing the most suitable, efficient, and environmentalfriendly dry hopping process for their brewery, this work approaches the main variables that promote aroma transfer from hops into beer and how to optimize it.
\end{abstract}

Keywords: dry hopping; hopped beer; hop.

Practical Application: A review about the methodologies of dry hopping process applied to industrial brewing process.

\section{Introduction}

Beer is made from four main ingredients, water, barley malt, hops and yeast. Hops are the female inflorescence of the hop plant (Humulus lupulus L.), known as hop cones. Hop cones have glandular trichomes commonly known as lupulin gland where secondary metabolites of interest for brewing are accumulated. These metabolites are essential oils (mostly terpenes, sesquiterpenes and their oxygenated analogous, terpenoids and sesquiterpenoids), phenolic compounds, alpha-acids and beta-acids (Cattoor et al., 2013). Hop cones are used in beer as it provides components that improve microbiological stability, foam, aromas, flavor and bitterness (Schmidt \& Biendl, 2017; Silva Ferreira et al., 2018). Beer bitterness comes mostly from the isomerization reaction of hop alpha acids (AA); these molecules have low solubility in water and during the boiling process they are converted into iso-alpha acids (IAA), a soluble molecule that provides the characteristic beer bitterness (Kunze, 2004).

There are several hop varieties available on the market. Each variety has its own unique characteristics, with different composition and concentrations of essential oils and resins (Palmer, 2006). The area and quantity at the global level tends to increase and mainly to a greater production of aroma hops (with a higher content of essential oils) (Bocquet et al., 2018). To enhance aroma, as essential oils are very volatile, hops are added at the end of the boiling or in the whirlpool (late hopping) or during fermentation and maturation (dry hopping).

Dry hopping (DH) is the cold extraction of volatile and nonvolatile hop compounds in an alcoholic solution, a technique used by brewers to increase the aroma and stability of beer flavor (Rettberg et al., 2018; Lafontaine et al., 2018). This extraction is optimized when using pellets or hop powder because both contain the crushed lupulin gland, increasing the contact surface. Because it is a cold extraction, its aromas differ significantly from those of late hopping, and may even be rich in terpene hydrocarbons (Rettberg et al., 2018).

As hoppy beer styles increased in popularity with consumers throughout the 21st century, brewers from the craft beer industry have been using dry hopping at an increasing rate (Lafontaine \& Shellhammer, 2018). Brewing scientists have been studying this technique in order to better understand the process and its impact on beer. The focus of the studies are on different brewing parameters such as flowers or pellets (Ceola et al., 2019), contact time and temperature (Oladokun et al., 2017), and methods of dry (Podeszwa \& Harasym, 2016; Lafontaine \& Shellhammer, 2018). Other awareness raised and researched are the ones concerning environmental and health hazard issues, such as presence of pesticides in hops and whether they can be found in beer (Kippenberger et al., 2014) and reuse of DH spent hops (Hauser et al., 2019).

Due to the growing consumption of hopped beers, brewers are looking for the best way to do dry hopping and achieve the desired aroma profiles. In order to shed light on this trending topic and to better aid brewers in choosing the most suitable dry hopping process in a more efficient fashion and more environmentally-friendly way, this work approaches the main

${ }^{2}$ Laboratório de Bioprocessos Cervejeiros e Catálise em Energias Renováveis, Instituto de Química, Universidade de Brasília - UNB, Campus Darcy Ribeiro, Brasília, DF, Brasil

${ }^{3}$ Universidade do Estado de Santa Catarina - UDESC, Campus Joinville, Joinville, SC, Brasil

*Corresponding author: ghesti.grace@gmail.com, grace@unb.br 
variables that promote aroma transfer from hops into beer and how to optimize the process.

\section{Beer production}

Beer production worldwide was growing until 2012 when it reached its peak with about 200 billion liters annually, since then the produced volume has been stable (Barth-Haas Group, 2018). Meanwhile, Brazilian beer market on the other hand has been gradually rising, mostly due to the rise in the craft beer industry, $23 \%$ each year (Lima et al., 2017). Hoppy beer production with or without dry hopping has increased in the last decade both in Brazil and overseas. In Brazil, this growth followed the growth of the number of micro and small breweries (Marcusso \& Müller, 2019). The biggest impact on the growth in consumption of more hopped beers is the global impact on hop production.

The addition of hops to the wort can also be done at the end of the boil or during the whirlpool, known as late hopping. The goal of late hopping is to have the shortest time of contact possible at high temperatures, thus reducing the loss of aromatic components. Aromatic beers are usually obtained by multiple late hop additions (Rettberg et al., 2018). The aromas retained in this process are closer to those present in the cone or pellet (Holt et al., 2019). Late hopping gives beer aromas of spicy, noble, herbal, woody, and even fruity character (Rettberg et al., 2018). Unlike hops added in the brewing room, in which molecules undergo oxidation reactions and may have their flavors and aromas altered, hop addition in the cold room provides flavors and aromas similar to that of fresh hops (Holt et al., 2019). The most used flavors to describe dry hopping are citrus, floral, and pine, differing from the traditional kettle-hopped beer (Rettberg et al., 2018). The main hop addition moments are represented in Figure 1.

\subsection{Hop products}

In order to better use hop cones in breweries, many products from hops have been developed, although most are meant for breweries use, some are used by the pharmaceutical industry. Regarding the beer industry, hop pellets are by far the most used, but the others have their importance too. Among the advantages of using hops products, the main ones are reduced transport and storage price, standardization of bitterness and aroma, improving bitterness yield, possibility of automatization, better use of fresh hops in overproduction years, and less dependency on current fluctuations if bought in bulk and stored (Kunze, 2004). On the other hand, pellets have a slightly more oxidized aroma profile, with more oxygenated hydrocarbons in its composition (Wolfe et al., 2012; Ceola et al., 2019).

\subsection{Whole cones}

The first way of adding hops into the brewing process was using the freshly harvested cone. Nowadays such use of whole or milled fresh cones are rare as they have very little shelf-life, so only breweries near hop farms are able to brew it. Some breweries though still use dried cones stored under vacuum as they have longer shelf-life and are less prompt to deterioration from oxygen, insects and fungi. To better disperse the hops, breweries often mill them just prior to use, but yet cones still are little used compared to pellets.

\subsection{Pellets}

In order to have an even longer shelf-life than dried whole cones, hop industries receive bales (compressed bulks of dried whole cones) from farmers, mill and compress the powder into pellets. This results in a much higher bulk density than the cone and it is easier dispersed into the hot wort or into green beer. Commercial interest in dry hopping is leading researchers, brewers and the hop industry into ways to maximize hop aroma retention during processing (hop drying, kilning, milling). For cold additions, as in dry hopping, dispersibility can be affected by the pellet properties, particularly the pellet density. (Benitez et al., 1997). Denser pellets experience higher temperature during formation, which could result in a change

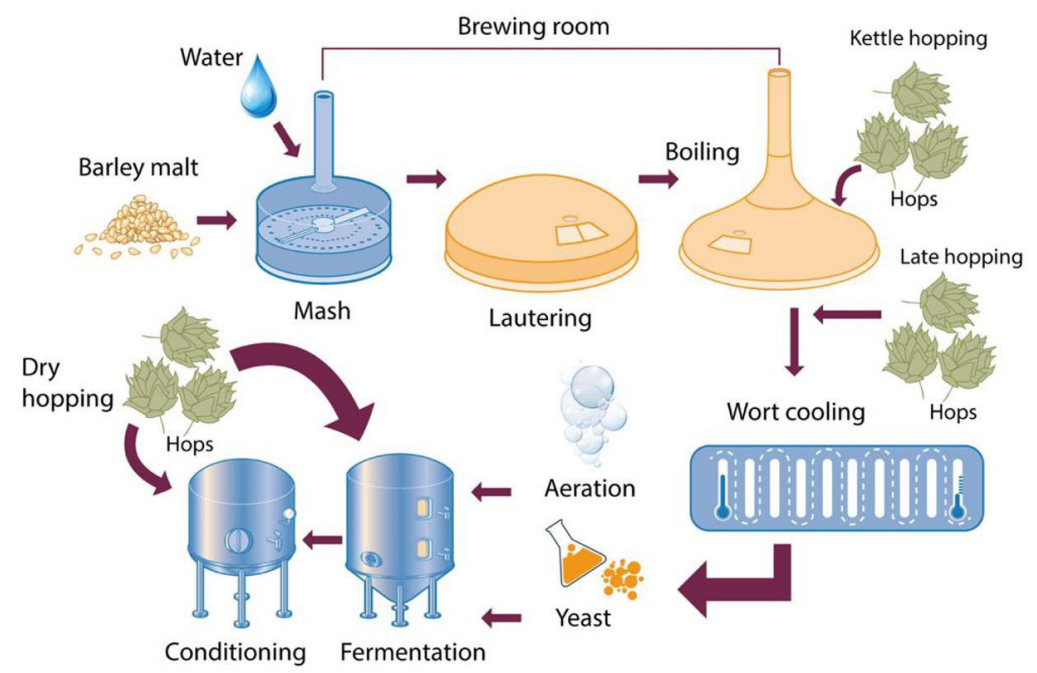

Figure 1. Brewing process illustration highlighting common hop additions. Source: Adapted from Ghesti et al. (2018). 
in the essential oils profile due to chemical rearrangements and oxidation. It is recognized as good manufacturing practice to maintain the pellet temperature between $38{ }^{\circ} \mathrm{C}$ and $50{ }^{\circ} \mathrm{C}$. Operating in this range ensures that the lupulin glands remain liquid but excessive losses of $\alpha$-acids and essential oils do not occur (Sidor, 2006).

Pellets are more readily extracted due to their particle size distribution and density. Particle size depends mostly on the milling process. Smaller particles have higher surface/volume ratio, their lupulin glands have been crushed and are more evenly distributed throughout the pellet, increasing the interaction with the solvent and dispersing their contents (Wolfe et al., 2012).

Pellets can also be further treated as to have iso-alpha acids, known as isopellets. This product has standardized iso-alpha acids content, but cannot be used in Germany or in breweries throughout the world which brew in accordance to the German purity law, Reinheitsgebot. Other hop products are available on the market, but regarding dry hopping these are the most important ones.

\subsection{Yeast and biotransformation}

From a brewer's perspective, this interaction is often between hop essential oils (terpenes and sesquiterpenes) and yeast (Saccharomyces sp.) enzymes because biotransformation is chemical modification made by an organism on a compound. Monoterpenes can suffer hydrolysis, reduction or even be arranged into others. Terpenes are very odor active molecules and changing their composition or chain alters the odor profile. Both lager and ale yeast can biotransform hop alcohol terpenes (geraniol and linalool). Oxygenated terpenes were less prompt to be biotransformed, thus lasted longer than hydrocarbon ones (King \& Dickinson, 2003).

Although there are several studies mentioning the biotransformation of hops compounds by yeast, few have shown the applicability in daily brewing. On laboratory scales, biotransformations of monoterpenic alcohols, classes of oxygenates and sesquiterpenoids are known to occur. It is essential to stimulate new research of interest to the brewing industry, helping to improve processes of transfer and aromatic control of beer (Praet et al., 2012).

Yeast reuse is shown to be compromised when using static dry hopping, it is necessary to remove the yeast biomass before adding the DH hops. In dynamic dry hopping, the removal of biomass is facilitated, as the $\mathrm{DH}$ process is done after the fermentable activity is finished.

\subsection{Dry hopping}

Scientific advances in the $\mathrm{DH}$ process go hand in hand with the development of analytical methods for beer. Recently, an "electronic nose" was used for the first time with short gas chromatography columns and flame ionization detectors. The advantages of the electronic nose include high sensitivity, and ease of use. However, more attention is still needed to optimize the method, to the point of making it robust and standardized (Štefániková et al., 2020).
Dry hopping efficiency depends on several factors, the most important being the amount of hops, number of additions (single or multiple addition), contact time, temperature, the regime (static or dynamic), and hop characteristics (pellet density, polyphenols, alpha acids, and essential oils content). The $\mathrm{pH}$ of beer increases after DH (Oladokun et al., 2017). Scientific advances in the $\mathrm{DH}$ process go hand in hand with the development of analytical methods for beer. Recently, an "electronic nose" was used for the first time with short gas chromatography columns and flame ionization detectors. The advantages of the electronic nose include high sensitivity, and ease of use. However, more attention is still needed to optimize the method, to the point of making it robust and standardized (Štefániková et al., 2020).

In terms of the extraction process, $\mathrm{DH}$ methods can be divided into static (Lafontaine \& Shellhammer, 2018) and dynamic (Podeszwa \& Harasym, 2016) methods. Each method gives distinct characteristics to the product, this is due to the contact time and the increase in the contact surface between the hops and the beer (Podeszwa \& Harasym, 2016).

When it comes to bittering, DH beers differ from kettle hopped beers. DH beers incorporate humulinones from hops which have a bitter taste. As humulinones are oxidized alpha acids, higher AA varieties will have more humulinones, as do older hops. This class of compounds are insoluble at high temperatures, therefore their effect in kettle hop additions are negligible. Algazzali \& Shellhammer (2016) carried out the most recent study on the relative bitterness of iso-alpha acids, humulinones and hulupones (names given to the oxidized forms of alpha and beta acids, respectively). The authors reported that humulinones have $66 \%$ of the bitterness of iso-alpha acids and hulupones $84 \%$. The oxidation reactions of these compounds are shown in Figure 2.

The goal of dry hopping is to enhance the hop aroma, therefore varieties with higher contents of essential oil are preferred, in many cases, low AA ones. Breweries vary considerably the amount used per recipe. It is important for the brewer to understand the chemistry of hops so as not to overdose the amount of hops in DH. Higher quantities of hops led to a stronger herbal/tea aroma and inefficient extraction, whereas lower had a lower aroma in general.

\subsection{Pesticides}

Kippenberger et al. (2014) presented the first scientific study of pollutant transfer during dry hopping. They related that dry hopping did not lead to a significantly elevated pesticide contamination compared to non-dry hopped beer. Therefore the concentration of plant protecting substances to assess the marketability of a beer has to be considered in the same way it would have to be without dry hopping. Add to that, the brewing and dry hopping experiments clearly showed that with $88 \%$ extraction efficiency, brewers must assume a quantitative transfer of nitrate from hops to beer. Product safety at high hop dosages can be compromised. By the way, dry hopping did not lead to a significantly increased contamination with azoxystrobin, dimethomorph, myclobutanil and quinoxyfen. Due to their low 


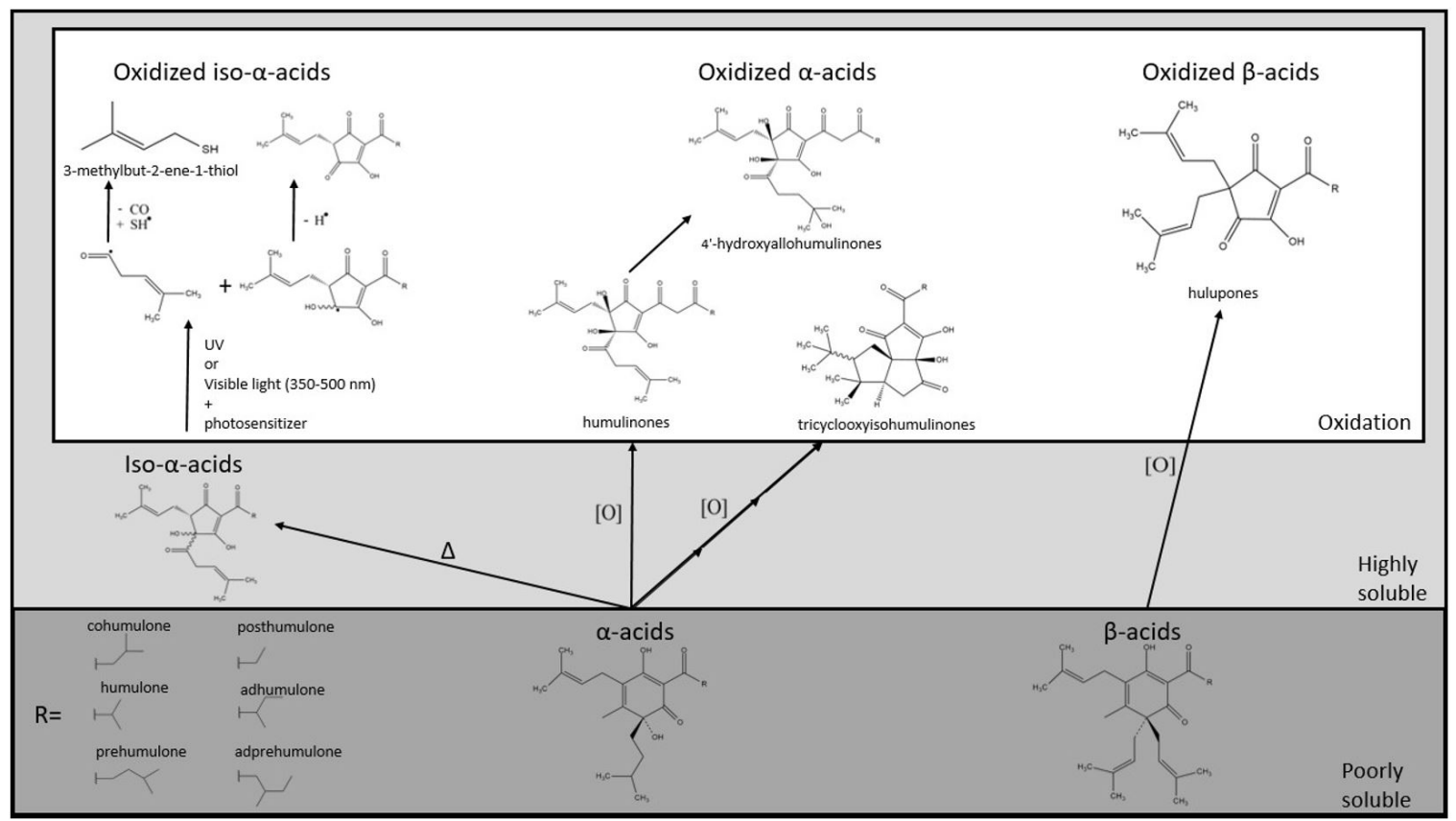

Figure 2. Isomerization reaction of alpha-acids into iso-alpha-acids, photolysis reaction of iso-alpha-acids, and oxidation reactions of alpha-acids to humulinones and beta-acids to hulupones. Source: De Keukeleire (2000); Jelínek et al. (2018).

water solubility, the beer saturated at very low concentrations and low hop dosages (Kippenberger et al., 2014).

\subsection{Hop creep}

Studies observing the fermentation of beer during the Dry Hopping effect started in 1891, with Brown and Morris (Kirkendall et al., 2018). For a long time, it was believed that the refermentation was due to the presence of sugars in the hops. However it has been shown that the enzymes in the hops are capable of hydrolyzing the beer dextrins, producing fermentable sugars in the finished beer, this process generates super-attenuation. Over-attenuation causes problems for brewers looking to meet brand specifications, such as specific density, flavor profile and alcohol content. An additional problem is the increase in $\mathrm{CO}_{2}$, overpressurizing the packaging, causing the cans and bottle caps to explode, a factor that is of concern to both distributors, retailers and customers. This phenomenon is called "hop creep". Kirkpatrick \& Shellhammer (2018) screened the enzymatic potential of dextrin degradation, showing the presence of $\alpha$-amylase, $\beta$-amylase, amyloglucosidase in hops samples.

Hop creep or freshening power is the name for the overattenuation when $\mathrm{DH}$ occurs at relatively high temperatures. Kirkendall et al. (2018) verified that the higher the temperature and the longer the contact rate, the more dextrins are broken down into fermentable sugars, which can be a problem for unpasteurized beers or even pasteurized beers with long shelflives. This extra sugar may cause a secondary fermentation, producing extra alcohol and carbon dioxide, which can even cause bottles to explode.

Initiatives from the Department of Food Science and Technology, Oregon State University, are comparing the impact of hops drying temperature on aromatic potential. Preliminary results showed that the high hop drying temperature significantly reduces enzyme and microorganism activity. Therefore, by varying the temperature of the hop drying ovens, it is possible to have more precise control for hop creep, without compromising the sensory quality of dry hopping (Lafontaine et al., 2019).

\subsection{Static and dynamic dry hopping}

Hop cones can be used instead of pellets, but the main goal here is marketing as cones have lower contact area and extraction yield, more leaf material and higher beer losses than pellets (Ceola et al., 2019). DH in itself is not very efficient, with approximately two thirds of the hop dry matter composition going to waste as hop spent regardless of the hop variety. Hop spent had $33 \%$ of AA in pilot scale and $48 \%$ in industrial scale, and half of hops essential oil in pilot scale, and two thirds in industrial. This means that many useful aroma and bitter compounds in the spent hops can be still used, either as material for another batch (Hauser et al., 2019) or for hop products.

Humulinones are naturally occurring oxidized bitter acids from hops. They can be found in hop leaves and their concentration may increase over time (Maye et al., 2016). Older hop cones and pellets - higher hop storage index (HSI) - have higher concentrations of humulinones than those with fresher hops (lower HSI). Maye et al. (2016) observed that high concentrations of humulinones have been found in $\mathrm{DH}$ commercial beers, reaching up to $24 \mathrm{ppm}$. Oladokun et al. (2017) studied the effects of temperature and alpha acids on DH over a 14 -day $\mathrm{DH}$ period. Dry hopping at higher temperatures $\left(17^{\circ} \mathrm{C}\right)$ with varieties rich in alpha acids resulted in a beer with more humulinone than using low alpha varieties or low temperatures. During the first $24 \mathrm{~h}$ of $\mathrm{DH}$, the authors observed the biggest drop in IAA concentration regardless of the conditions used, and most of the polyphenols extraction. IAA were adsorbed on 
the leaves and were accumulated in the spent hops. Alpha acids were only solubilized for high AA variety at high temperature. Many brewers are unaware that the acidic composition of hops during dry hopping can significantly change $\mathrm{pH}$ in beer (Maye et al., 2016), always to a higher one (Oladokun et al., 2017). High performance liquid chromatography (HPLC) was used to accurately measure the hop acid composition of dry hopped beers. Purified hop compounds were added to nondry hopped beers to simulate the hop acid composition of dry hopping beers. HPLC analysis of beers with large amounts of dry hopping showed that this process removes a considerable amount of iso-alpha-acids and adds less bitter alpha-acids and humulinones to beer. Both alpha-acids and humulinone acids are measured by the IBU test, but the result does not correctly correlate with bitterness sensation. This means that the IBU test is not useful for dry hopped beers. Spectrophotometric measured values do not correlate with bitterness and HPLC is too expensive for breweries to do routine analysis in their beers for a corrected IBU, taking into account iso-alpha-acids, alpha-acids and humulinones relative bitterness.

\subsection{DH scale-up}

Regarding DH in large breweries, the challenge of scaling up is a barrier to be overcome. The larger the scale, the more adjusts and studies to be able to reproduce the results. Moreover, this technique is commonly used for craft beers brewed in smaller volumes due to their higher value, loss of beer inherent to the $\mathrm{DH}$ process, and frequently by small and medium-sized breweries.

According to Schnaitter et al. (2016), the chemical composition and aromas of beer with dry hopping clearly depends on the scale at which it is performed because the mass-transfer rates of the hop aromatic compounds are not comparable in flavor and odor to those dry hopped on a laboratory scale. They related that the mass-transfer rates of the hop aromatic oils to the beer clearly depend on the scale of the trials. Which means studies must be done in loco for a better understanding of the process on an industrial scale, highlighting the need for collaboration between industry and academia.

Therefore, brewers cannot expect to achieve similar aroma impressions when scaling up laboratory-scale trials to industrialscale trials without adjusting the recipe. Furthermore, it would make sense to identify the parameters that influence the masstransfer rates from hops into beer. Possible parameters could be the varying headspace volume of the tanks used for $\mathrm{DH}$ because the concentrations of volatiles could be enriched in the gas phase above the fermented beverages (Mouret et al., 2014) and therefore the concentration in the liquid phase could decrease. Add to that, Wolfe (2012) already measured the extraction curves of hop volatiles using a model solution but only varied the hop-particle size distribution, which did not significantly affect the extraction rates of most volatiles. Unfortunately, all these studies did not continue investigating more process variables, in order to identify the main parameters that are responsible for the yield of hop oils extraction during dry hopping.

An interesting alternative to reduce the insertion of oxygen in the fermenter tank to make the dry hopping static during

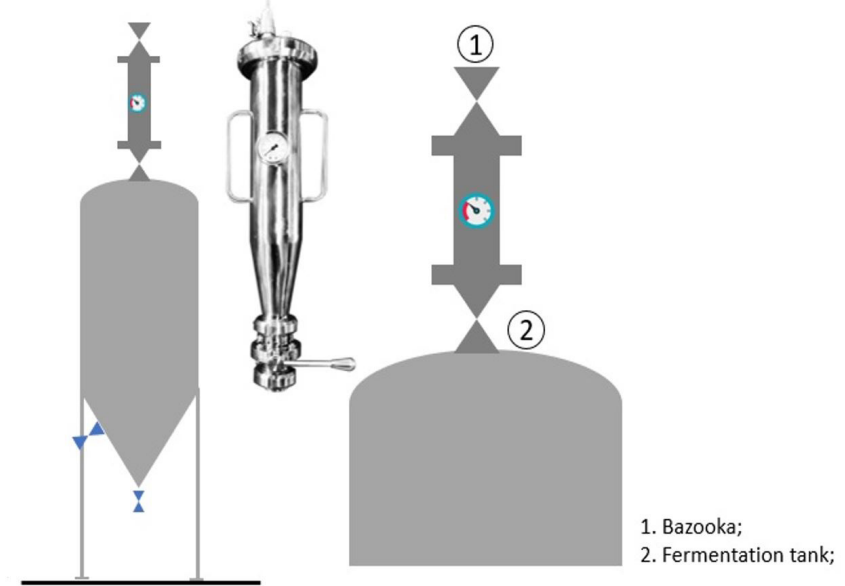

Figure 3. Bazooka: equipment for adding hops to static dry hopping without incorporation of oxygen.

fermentation is to use an equipment called bazooka as shown in the Figure 3, consisting of a stainless steel compartment attached to the top of the fermenter tank. The first step in the process is to fit the apparatus in the tank with the upper valve closed, add the hops and remove the oxygen with a $\mathrm{CO}_{2}$ purge. Leave it pressurized with the same pressure that is in the tank, open the valve so that gravity drops the pellets into the tank. It is an interesting alternative to reduce oxygen intake into the fermenting beer, but the major limitation is adapting the top for coupling the bazooka. Newer fermenter tank designs feature the coupling hatch and sell with the bazooka for easy handling.

\subsection{Disintegration stage of pellets}

During the $\mathrm{DH}$ process, the disintegration stage of the pellets is of great importance. The variables involving swelling speed, volume, pellet roughness, decanting speed and particle size distribution are considered to be the variables that require greater understanding. One fact that we must consider when doing DH is the mass transfer of aromatic compounds. Research shows that pellet swelling and disintegration occur simultaneously, the higher the temperature, the greater the swelling and disintegration speed. In analyzes related to the pellet swelling volume, it was observed that the higher the concentration of alpha acid, the greater the swelling speed. Pellet sedimentation is relatively fast, the dynamic dry hopping method should be considered to increase agitation, homogenizing the pellets, obtaining greater extraction yield. It is evident that the pelletizing process is an important step in the processing of hops, one of the most delicate steps. Depending on the shear force, a glassy film can be created on the outside of the pellet, this film is formed by heating the matrices of the pelletizing equipment. An alternative to avoid the formation of the film is to cool the dies. Significantly increasing disintegration in DH (Engstle et al., 2016).

\subsection{Dynamic dry hopping}

The idea of increasing the contact surface of the hops with beer arose from the need to develop a faster and more efficient method to provide aroma in beer (Hieronymus, 2012). 
The classic concept of $\mathrm{DH}$ is the addition of hops to the fermenting tank, considered as static dry hopping (Lafontaine et al., 2018). A new method was developed in 2016, using an external unit, the dry hopping time decreased considerably by conditioning the hops in a larger area of contact with beer (Podeszwa \& Harasym, 2016), as shown in Figure 4a. The reduction in the amount of hops used is a significant factor for the use of this method.

Some breweries use a plate filter to make dynamic $\mathrm{DH}$, as shown in Figure 4 b. Removal of oxygen is a fundamental step for this technique. Due to the increase in the contact area between hops and beer, the amount of hops can be reduced without compromising the sensory quality. Another advantage is in beer filtration as hops can replace diatomaceous earth.

\subsection{Static dry hopping}

The classic concept of DH is the addition of hops to the fermenting tank, considered as static DH, which according to studies has observed a more balanced flavor quality between 400 and 800 grams of hops per hectoliter (values above this dosage show decreasing returns in terms of increase in aroma). There is evidence that approximately $75 \%$ of humulinones are extracted in this technique (Lafontaine et al., 2018). Studies have reported that agitation alters the aroma characteristics of the extracted hop flavor to a more herbaceous character and promotes the extraction of polyphenols, which can increase the astringency of beer (Wolfe et al., 2012).

In order to better extract hop compounds in static $\mathrm{DH}$, some breweries purge $\mathrm{CO}_{2}$ under the fermentation or maturation tank to keep hops in suspension, as illustrated in Figure 5. This significantly increases hop aroma extraction due to increased contact surface as shown in Figure $4 \mathrm{~b}$. The major drawbacks from purging $\mathrm{CO}_{2}$ to resuspend hops are foaming and aroma lost from out in the process.

\section{Dry hopping - Iso-Mix External Drive (IMXD)}

A new method was approached in 2017 using a rotary mixer with a jet at its end positioned below the tank and an external unit facilitates the dispersion of hop solids in beer, allowing a reduction of hop dosage ( $>20 \%$ solids), accelerates breakdown and time savings of up to $15 \%$ (Hartvigsen, 2017). For the dry hopping process, this mixing setting keeps the hops in homogeneous suspension during the transfer of metabolites. Even though the implementation of a unit for Dry Hopping Iso-Mix External Drive (IMXD, Figure 6) has a high acquisition cost, it proved to be viable for plants with productive capacities above $100 \mathrm{hL}$ for the advantages in the applicability and reduced hop dosage.

\subsection{Beer packaging and industrial applications}

The beer loss during $\mathrm{DH}$ is estimated to be over $20 \%$ of the tank volume, what makes the process even more expensive. In large Brazilian breweries which seek higher hop flavor or aroma use hop extracts rather than pellets or cones as they have a higher yield and close to no loss. They use isomerized extracts, hop oils extract, different varieties extracts blends, reduced iso-alpha acids extract, etc.

Regarding packages, opaque ones i.e. cans, kegs or ambercolored glasses are recommended for beer as many hop molecules are sensible to both visible and UV light (350-500 $\mathrm{nm}$ ) which oxidize them (De Keukeleire, 2000). The major reaction is the oxidation of iso-alpha-acids. This reaction produces a free radical, which is then stabilized by a thiol group, yielding 3-methylbut-2-ene-1-thiol as a by-product (Zufall et al., 2008). This reaction is known as lightstruck and the smell of the thiol produced reminds of skunk and the detection threshold for its aroma is as low as some ppt (ng/L) (Steenackers et al., 2015). Another molecule that indicates the beer has oxidized is the one responsible for the aroma of cardboard, trans-non-2-enal. The incorporation of oxygen during $\mathrm{DH}$ might fast-forward the oxidation process and reduce the shelf-life of the product as the yeast metabolism is low, for this reason the brewer must purge $\mathrm{CO}_{2}$ into the vessel with hops prior to dry hopping. Terpene oxidized products tend to have a woody, spicy or even mouldy-like aroma, very different from the commonly wanted fruity and citrusy aromas (Rettberg et al., 2018). Although it is known old hops have cheese, sweaty-like aromas (isovaleric
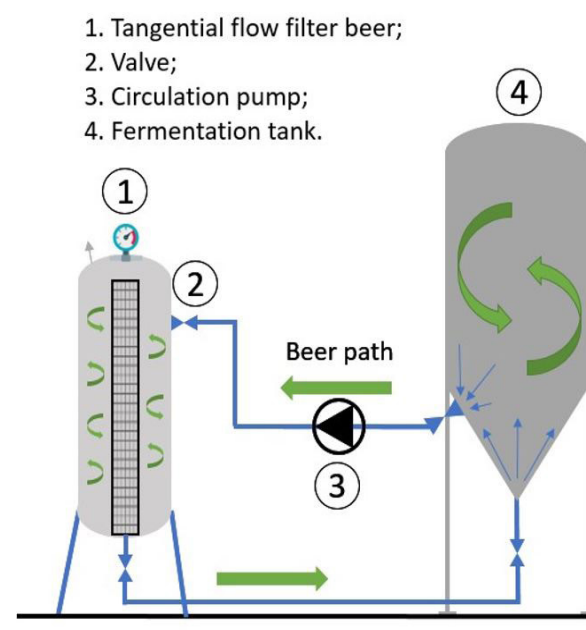

(A)

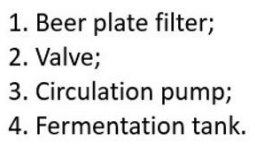

(1)

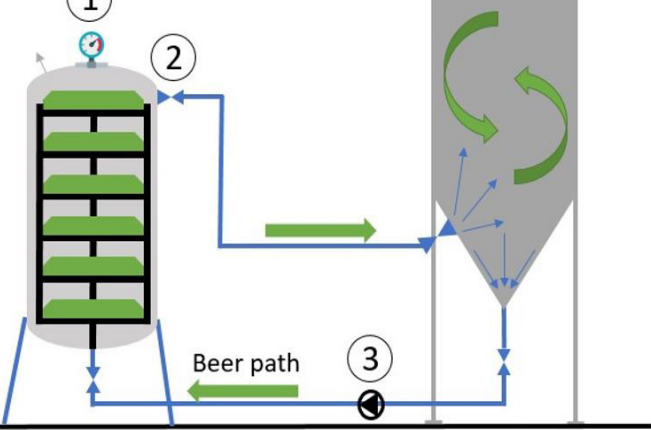

(B)

Figure 4. Dynamic dry hopping: dosing and recirculation system using (A) tangential flow and (B) filters. 


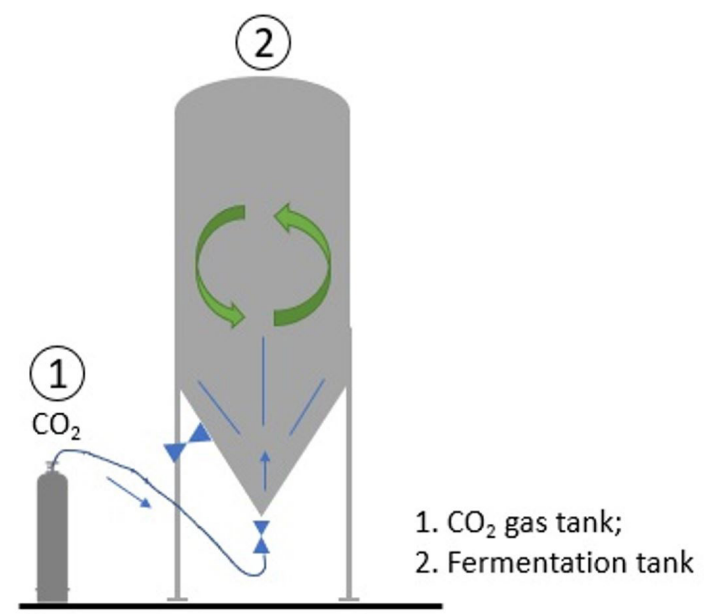

Figure 5. Static dry hopping: dosing device with added hop in the reservoir (dosing with $\mathrm{CO}_{2}$ injection).

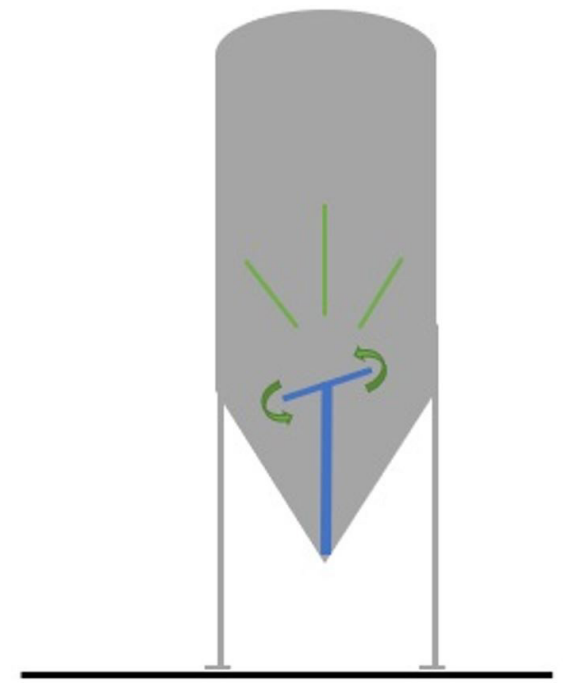

Figure 6. Improvements with the Iso-Mix external drive (IMXD) compared with conventional dry hopping processes.

acid) due to oxidation (Lafontaine et al., 2019), little is known whether these same off-aromas can be formed in old DH beers.

Hop aroma composition in DH beer is composed of thousands of different substances, each of which has individual properties in terms of sensory qualities, solubility, volatility, and polarities. Recent studies demonstrated that part of the products discarded in the dry hopping process retains valuable volatile and nonvolatile components of hops, this opens up the possibility of recovering both the bitter and aromatic potentials of what would otherwise be a residue of the production process (Hauser et al., 2019). Based on this, the chosen dry hopping technique can minimize such losses in this step.

\section{Conclusions}

Dry hopped beer production has increased steadily over the last 20 years, following the rise of craft breweries in the United States and the trend they set over the world. Dry hopping is size-dependent, making it feasible for craft breweries with small tanks but offers quite a challenge for larger tanks and breweries. Challenges are the driving force of the scientific community, which seeks to develop more ecofriendly and efficient ways to obtain higher yields and reuse of spent hops. Recent research has shown that, despite the potential for unsustainable brewing practices, many regional craft brewers are succeeding in assessing the potential impacts of their production processes and implementing changes for better environmental, economic and social sustainability.

Static dry hopping technique with $\mathrm{CO}_{2}$ purges from the bottom of the fermenting tank showed a significant increase in the aromatic profile. It is widely used in small and large breweries, as it has a more accessible cost. In order to achieve better results, dynamic dry hopping was developed. It has a slightly higher installation cost due to readjustment and acquisition of equipment, on the other hand, it provides greater dissolution of the hops, shorter process times and studies showed a reduction up to $50 \%$ in hops consumption compared to static dry hopping. Iso-Mix External Drive is only feasible for beer plants above 100 HL due to its high acquisition cost. Data published in research report savings of over $20 \%$ in hop dosage and a $15 \%$ reduction in time due to better dispersion of hop solids in beer.

\section{References}

Algazzali, V., \& Shellhammer, T. (2016). Bitterness intensity of oxidized hop acids: humulinones and hulupones. Journal of the American Society of Brewing Chemists, 74(1), 36-43. http://dx.doi.org/10.1094/ ASBCJ-2016-1130-01.

Barth-Haas Group. (2018). Hops. Retrieved from https://www. barthhaasgroup.com/images/mediacenter/downloads/pdfs/412/ barth-bericht20172018en.pdf

Benitez, J. L., Forster, A., De Keukeleire, D., Moir, M., Sharpe, F. R., Verhagen, L. C., \& Westwood, K. T. (1997). European brewery convention manual of good practice: hops and hop products. Nürnberg: Fachverlag Hans Carl.

Bocquet, L., Sahpaz, S., \& Rivière, C. (2018). An overview of the antimicrobial properties of hop. In J. M. Mérillon \& C. Riviere (Eds.), Natural antimicrobial agents (pp. 31-54). Cham: Springer. http://dx.doi.org/10.1007/978-3-319-67045-4_2.

Cattoor, K., Dresel, M., De Bock, L., Boussery, K., Van Bocxlaer, J., Remon, J. P., De Keukeleire, D., Deforce, D., Hofmann, T., \& Heyerick, A. (2013). Metabolism of hop-derived bitter acids. Journal of Agricultural and Food Chemistry, 61(33), 7916-7924. http://dx.doi. org/10.1021/jf300018s. PMid:23898921.

Ceola, D., Huelsmann, R. D., Da-Col, J. A., \& Martendal, E. (2019). Headspacesolid phase microextraction and GC-MS followed by multivariate data analysis to study the effect of hop processing type and dry hopping time on the aromatic profile of top-fermented beers. Separation Science Plus, 2(7), 245-252. http://dx.doi.org/10.1002/sscp.201900012.

De Keukeleire, D. (2000). Fundamentals of beer and hop chemistry. Quimica Nova, 23(1), 108-112. http://dx.doi.org/10.1590/S010040422000000100019.

Engstle, J., Kuhn, M., Kohles, M., Briesen, H., \& Först, P. (2016). Disintegration of hop pellets during dry hopping. Brewing Science, 11-12(69), 123-127. Retrieved from https://www.researchgate.net/publication/312626359_ Disintegration_of_Hop_Pellets_during_Dry_Hopping

Ghesti, G., Barros, C., Muller, C., Parachin, N., \& Pinheiro, L. (2018). Análise sensorial para cervejas (Master's thesis). Universidade 
de Brasília, Brasília. Retrieved from https://repositorio.unb.br/ handle/10482/37862

Hartvigsen, A. (2017). Revolutionary dry-hopping techniques for larger beer volumes using the iso-mix external drive rotary jet mixer. St. Paul: Master Brewers Association of the Americas. http://dx.doi. org/10.1094/TQ-54-4-1122-01.

Hauser, D. G., Lafontaine, S. R., \& Shellhammer, T. H. (2019). Extraction efficiency of dry-hopping. Journal of the American Society of Brewing Chemists, 77(3), 188-198. http://dx.doi.org/10.1080/03610470.201 9.1617622 .

Hieronymus, S. (2012). For the love of hops: the practical guide to aroma, bitterness and the culture of hops. Boulder: Brewers Publications.

Holt, S., Miks, M. H., Carvalho, B. T., Foulquié-Moreno, M. R., \& Thevelein, J. M. (2019). The molecular biology of fruity and floral aromas in beer and other alcoholic beverages. FEMS Microbiology Reviews, 43(3), 193-222. http://dx.doi.org/10.1093/femsre/fuy041. PMid:30445501.

Jelínek, L., Müllerová, J., Karabín, M., \& Dostálek, P. (2018). The secret of dry hopped beers: review. Kvasny Prumysl, 64(6), 287-296. http:// dx.doi.org/10.18832/kp201836.

King, A. J., \& Dickinson, J. R. (2003). Biotransformation of hop aroma terpenoids by ale and lager yeasts. FEMS Yeast Research, 3(1), 53-62. http://dx.doi.org/10.1016/S1567-1356(02)00141-1. PMid:12702246.

Kippenberger, M., Hanke, S., Biendl, M., Stettner, G., \& Lagemann, A. (2014). Transfer of nitrate and various pesticides into beer during dry hopping. Brew Sci, 67, 1-9.

Kirkendall, J. A., Mitchell, C. A., \& Chadwick, L. R. (2018). The freshening power of Centennial hops. Journal of the American Society of Brewing Chemists, 76(3), 178-184. http://dx.doi.org/10.1 080/03610470.2018.1469081.

Kirkpatrick, K. R., \& Shellhammer, T. H. (2018). Evidence of dextrin hydrolyzing enzymes in cascade hops (Humulus lupulus). Journal of Agricultural and Food Chemistry, 66(34), 9121-9126. http://dx.doi. org/10.1021/acs.jafc.8b03563. PMid:30084254.

Kunze, W. (2004). Brewing malting (pp. 18-152). Berlin: VLB.

Lafontaine, S. R., \& Shellhammer, T. H. (2018). Impact of static dry-hopping rate on the sensory and analytical profiles of beer. Journal of the Institute of Brewing, 124(4), 434-442. http://dx.doi. org/10.1002/jib.517.

Lafontaine, S. R., Hauser, D. G., Foster, R., Donaldson, J., Gamache, D., \& Shellhammer, T. H. (2018). Impact of kiln temperatures on the aroma and enzymatic potential of hops during dry-hopping. In Recent Advances in Hop Science. Brussels: European Brewery Convention. Retrieved from https://www.researchgate.net/profile/Scott_Lafontaine2/ publication/327755590_Impact_of_kiln_temperatures_on_the_ aroma_and_enzymatic_potential_of_hops_during_dry-hopping/ links/5ba2b05492851ca9ed173e2c/Impact-of-kiln-temperatures-onthe-aroma-and-enzymatic-potential-of-hops-during-dry-hopping.pdf

Lafontaine, S., Varnum, S., Roland, A., Delpech, S., Dagan, L., Vollmer, D., Kishimoto, T., \& Shellhammer, T. (2019). Impact of harvest maturity on the aroma characteristics and chemistry of Cascade hops used for dry-hopping. Food Chemistry, 278, 228-239. http:// dx.doi.org/10.1016/j.foodchem.2018.10.148. PMid:30583367.

Lima, L. A., Fernandes, T. L., Tenório, L. X. S., Silva, M. L., Evaristo, R. B. W., Ghesti, G. F., \& Martin, A. R. (2017). Sinopse do cenário cervejeiro: o advento da produção e o mercado na região centro oeste. Cadernos de Prospecção, 10(4), 650. http://dx.doi.org/10.9771/cp.v10i4.23041.

Marcusso, E. F., \& Müller, C. V. (2019). Anuário da cerveja no Brasil 2018: crescimento e inovação. Brasília: Ministério da Agricultura, Pecuária e Abastecimento. Retrieved from http://www.agricultura. gov.br/assuntos/nuário/produtos-vegetal/pasta-publicacoes-DIPOV/ nuário-da-cerveja-no-brasil-2018/view
Maye, J. P., Smith, R., \& Leker, J. (2016). Humulinone formation in hops and hop pellets and its implications for dry hopped beers. MBAA TQ, 53(1), 23-27. http://dx.doi.org/10.1094/TQ-53-1-0227-01.

Mouret, J. R., Camarasa, C., Angenieux, M., Aguera, E., Perez, M., Farines, V., \& Sablayrolles, J. M. (2014). Kinetic analysis and gasliquid balances of the production of fermentative aromas during winemaking fermentations: effect of assimilable nitrogen and temperature. Food Research International, 62, 1-10. http://dx.doi. org/10.1016/j.foodres.2014.02.044.

Oladokun, O., James, S., Cowley, T., Smart, K., Hort, J., \& Cook, D. (2017). Dry-hopping: the effects of temperature and hop variety on the bittering profiles and properties of resultant beers. BrewingScience, 70(6), 187-196. http://dx.doi.org/10.23763/BrSc17-18oladokun.

Palmer, J. J. (2006). How to brew: everything you need to know to brew beer right the first time. Boulder: Brewers Publications.

Podeszwa, T., \& Harasym, J. (2016). New methods of hopping (dryhopping) and their impact on sensory properties of beer. Acta Innovations, (21), 79-86. Retrieved from https://www.researchgate. net/publication/314231904_New_methods_of_hopping_dryhopping and_their_impact_on_sensory_properties_of_beer

Praet, T., Van Opstaele, F., Jaskula-Goiris, B., Aerts, G., \& De Cooman, L. (2012). Biotransformations of hop-derived aroma compounds by Saccharomyces cerevisiae upon fermentation. Cerevisia (Gedrukt), 36(4), 125-132. http://dx.doi.org/10.1016/j.cervis.2011.12.005.

Rettberg, N., Biendl, M., \& Garbe, L. A. (2018). Hop aroma and hoppy beer flavor: chemical backgrounds and analytical tools: a review. Journal of the American Society of Brewing Chemists, 76(1), 1-20. http://dx.doi.org/10.1080/03610470.2017.1402574.

Schmidt, C., \& Biendl, M. (2017). LC-MS/MS analysis of hop flavonoids in dry-hopped beers. Monatsschrift fur Brauwissenschaft, 70, 197-202.

Schnaitter, M., Kell, A., Kollmannsberger, H., Schüll, F., Gastl, M., \& Becker, T. (2016). Scale-up of dry hopping trials: importance of scale for aroma and taste perceptions. Chemieingenieurtechnik, 88(12), 1955-1965. http://dx.doi.org/10.1002/cite.201600040.

Sidor, L. (2006). Hops and preparation of hops. Raw Materials and Brewhouse Operations, 1, 73-109.

Silva Ferreira, C., Thibault de Chanvalon, E., Bodart, E., \& Collin, S. (2018). Why humulinones are key bitter constituents only after dry hopping: comparison with other Belgian styles. Journal of the American Society of Brewing Chemists, 76(4), 236-246. http://dx.doi. org/10.1080/03610470.2018.1503925.

Steenackers, B., De Cooman, L., \& De Vos, D. (2015). Chemical transformations of characteristic hop secondary metabolites in relation to beer properties and the brewing process: a review. Food Chemistry, 172, 742-756. http:// dx.doi.org/10.1016/j.foodchem.2014.09.139. PMid:25442616.

Štefániková, J., Nagyová, V., Hynšt, M., Kudláková, D., Árvay, J., \& Dráb, Š. (2020). A comparison of sensory evaluation and an electronic nose assay in the assessment of aroma in dry hopped beers. Kvasny Prumysl, 66(1), 224-231. http://dx.doi.org/10.18832/kp2020.66.224.

Wolfe, P. H. (2012). A study of factors affecting the extraction of flavor when dry hopping beer (Master's thesis). Oregon State University, Corvallis.

Wolfe, P., Qian, M. C., \& Shellhammer, T. H. (2012). The effect of pellet processing and exposure time on dry hop aroma extraction. In M. C. Qian \& T. H. Shellhammer (Eds.), Flavor chemistry of wine and other alcoholic beverages (pp. 203-215). Washington: American Chemical Society. http://dx.doi.org/10.1021/bk-2012-1104.ch013.

Zufall, C., Wackerbauer, K., \& Brandt, C. (2008). The influence of hop products on beer flavour stability. Brewing Science, 11(12), 113-120. Retrieved from https://www.researchgate.net/publication/295767807_ The_influence_of_hop_products_on_beer_flavour_stability 